\title{
The Effect of Teacher-Parent Partnership and Childcare Center Organizational Culture on Teacher Efficacy
}

\author{
보육교사가 인식한 교사-부모 파트너십과 \\ 어린이집 조직문화가 교사효능감에 미치는 영향
}

Hyun-Joo Kang ${ }^{1}$, Sung-On Hwang ${ }^{2}$

강현주 1 , 황성온 2

${ }^{1}$ Graduate Student, Department of Child Psychology, Inha University, hyunjoodang@naver.com

${ }^{2}$ Professor, Early Childhood Education, Incheon National University, Korea, hso@inu.ac.kr

Corresponding author: Sung-On Hwang

\begin{abstract}
The purpose of this study is to determine the impact of teacher-parent partnership and childcare center organizational culture on childcare teachers' efficacy. The survey was conducted on 241 teachers working in childcare centers in I city who were chosen through convenience sampling. The collected data were analyzed using the program SPSS 22.0. Cronbach's $\alpha$ coefficient was estimated for the reliability of the research instruments and Pearson's correlation analysis was carried out to find out the correlation between research variables. Lastly, multiple regression analysis was also performed to determine the relative influence of teacher-parent partnership and childcare center organizational culture on childcare teacher's efficacy. The results of this study can be summarized as follows. First, a positive correlation was found between teacher-parent partnership and childcare center organizational culture, teacher's efficacy. Second, the relative impact of teacher-parent partnership and rational culture among those for organizational culture were also found to have the on childcare teacher's efficacy had meaningful explanatory power. The teacher-parent partnership had a relatively greater influence on teacher efficacy than rational culture among organizational culture. These results suggest that teacherparent partnership and rational culture can be important factors for childcare teacher's efficacy. The results of the study are intended to provide basic data to help improve the quality of childcare services by finding ways to improve the teacher efficacy of childcare center teachers.
\end{abstract}

Keywords: Teacher-Parent Partnership, Organizational Culture, Teacher Efficacy, Childcare Teacher

요약: 본 연구는 보육교사가 인식한 교사-부모 파트너십과 어린이집 조직문화가 교사효능감에 미치는 상대적 영향력을 알아보는 데 그 목적이 있다. 이를 위하여 I 시에 소재한 어린이집에서 근무 중인 보육교사 241 명을 대상으로 설문조사를 실시하였다. 수집된 자료는 SPSS 22.0 프로그램을 사용하여 통계처리 하였다. 측정 도구의 신뢰도 검증을 위해서 Cronbach's a 계수를 산출하였으며 Pearson의 상관분석과 다중회귀분석을 실시하였다. 자료 분석 결과는 다음과 같다. 첫째, 교사-부모 파트너십과 어린이집 조직문화(관계, 개발, 위계, 합리문화), 교사효능감 간에 모두 통계적으로 유의미한 정적 상관관계가 있는 것으로 나타났다. 둘째, 교사-부모 파트너십과 어린이집 조직문화 중 합리문화는 보육교사의

Received: August 10, 2021; $1^{\text {st }}$ Review Result: September 26, 2021; $2^{\text {nd }}$ Review Result: November 15, 2021 Accepted: December 31, 2021

*This article is a part of Hyun-Joo Kang's master's thesis submitted in 2020. 
교사효능감을 예측하는 변인이며, 교사-부모 파트너십이 어린이집 조직문화의 합리문화보다 교사효능감에 미치는 영향력이 더 큰 것으로 나타났다. 이러한 결과는 교사-부모 파트너십과 어린이집의 합리문화가 교사효능감에 중요한 예측 변인임을 시사한다. 본 연구결과를 통해 보육교사의 교사효능감 증진을 위한 방안이 모색됨으로써 보육 서비스의 질적 향상에 도움을 주는 기초자료로 활용될 수 있을 것으로 기대된다.

핵심어: 교사-부모 파트너십, 어린이집 조직문화, 교사효능감, 보육교사

\section{1. 서론}

현대사회는 여성의 경제활동 참여율 증가로 인해 가정의 '자녀 양육' 기능이 약화하면서 사회, 국가적 차원에서 다양한 보육 서비스의 필요성을 강조하고 있다. 선진 국들은 미래의 국가 경쟁력을 높이기 위하여 인간의 기본 잠재력이 결정되는 영유아기에 관한 보육정책에 대한 노력을 기울이고 있으며, 우리나라 역시 이러한 변화에 발맞추어 2012년부터 무상보육 실시정책을 통해 영유아보육기관에 대한 지원을 확대해 나가기 시작했다. 그 결과 보육기관의 양적팽창이 이루어졌으며, 양질의 보육 서비스를 제공하기 위해 보육 프로그램 및 보육교사의 전문성 향상을 위한 연구들이 활발히 진행되고 있다.

보육교사는 영유아들과 가장 가까이에서 많은 시간을 보내고 환경을 구성하며 보육 프로그램을 계획하고 실행하는 역할을 담당하고 있다. 영유아기는 발달적 측면에서 개인차가 존재하고 기질과 욕구에서의 편차가 크므로, 개개인과의 상호작용 및 적합한 교육과정 지원은 매우 중요한 부분이다. 그러므로 영유아의 발달수준을 올바르게 파악하고 그들의 필요한 부분을 정확히 인지하고 지원하는 전문성 있는 교사가 필요하다[1]. 이에 보육교사 전문성 향상과 관련하여 핵심적 요소로 주목받고 있는 교사효능감에 대해 알아볼 필요성이 제기된다.

교사효능감은 Bandura(1997)[2]의 자아효능감 이론에서 그 근원을 찾을 수 있다. Ashton(1984)[3]은 보육교사의 교사효능감이란, 교사 스스로가 영유아들의 행동에 큰 영향을 미칠 수 있는 능력을 지니고 있다고 믿는 신념으로, 교사 행동의 질을 결정하는 중요한 요인이라고 하였다. 교사효능감은 교사 스스로 영유아들에게 다양한 경험을 제공하고 효율적인 교수 방법으로 지도하려는 동기를 부여하며, 영유아가 흥미를 갖고 교수 활동에 참여할 수 있도록 지원하고자 하는 교사의 의지에 영향을 주기도 한다[4].

Ashton(1984)[3]에 의하면 교사효능감이 높은 교사는 교사효능감이 낮은 교사에 비해 관대하며, 모든 학습자에게 주의를 기울이고, 격려함으로써 긍정적인 교육환경을 조성하고자 노력한다고 하였다. 반대로 교사효능감이 낮은 교사는 영유아의 능동적 참여를 지지하고 격려하는 태도보다 지시나 통제를 이용하여 가르치는 행동을 하므로 영유아의 놀이를 위축시킬 수 있다고 하였다[5].

교사효능감에 관한 국내 선행연구를 살펴보면 김사녀(2012)[6], 김유정, 박지혜, 안선희(2012)[7]는 교사효능감이 높은 교사는 부모와 효과적인 소통을 함으로써 교사로서 긍정적으로 역할을 수행한다고 하였고, 임우영과 안선희(2011)[8]는 교사효능감이 높으면 부모-교사 간 협력적 관계가 잘 형성되어 교사와 영유아 간 부정적인 상호작용이 감소한다고 하였다. 강찬미(2017)[9]는 교사와 부모 간에 협력관계가 형성되면 학습자에 대한 이해를 증진하게 시켜 교사효능감이 높아지고, 교사-영유아 상호작용에 더욱 바람직한 영향을 미친다고 하였다. 선행연구를 종합해보면 교사효능감은 교사-부모의 
협력관계와 매우 밀접한 관련이 있음을 예측할 수 있다.

영유아기 발달 특성을 고려할 때 기관과 가정의 연계 및 협력의 중요성은 매우 오랫동안 강조되어 왔다. 2015년 보건복지부는 보육환경 개선을 목적으로 부모가 보육기관의 운영 과정에 적극적으로 참여하도록 하는 '열린 어린이집'의 조성을 보육정책의 주요 목표로 설정한 바 있다. 이러한 보육정책은 교사-부모 파트너십을 통해 교사와 부모 간에 상호 지지적인 관계를 이루어 영유아의 성장과 발달을 지원하고, 부모가 보육기관을 보다 깊이 있게 이해하고 육아 정보를 공유하며, 가정-어린이집지역사회가 동반자적 관계를 이루어 안정된 양육환경을 제공하기 위함이다[10].

영유아기는 일생 중 발달이 가장 활발히 이루어지는 결정적 시기이므로 교사는 부모와 충분한 소통을 통하여 상호 협력적 파트너십을 형성함으로써, 영유아의 전인적 발달에 최적의 환경을 마련해 주어야 한다. 교사와 부모의 교육적 견해 차이가 벌어질수록 영유아의 불안감도 증가하기 때문에, 교사와 부모는 영유아의 발달에 있어 일관된 교육방식을 전달하고 공동의 책임감을 느끼고 동반자, 지지자, 촉진자의 역할을 수행해야 한다[11][12].

교사-부모 파트너십에 대한 선행연구를 살펴보면 이찬주(2012)[13]의 연구에서 부모의 연령과 교육 수준이 높을수록 교사와 상호 협력적인 관계를 형성한다는 연구 결과를 보고하였다. 함현정(2019)[14]은 교사-부모의 관계가 바람직하게 이루어지게 되면, 부모는 교육 프로그램을 보다 긍정적으로 수용하여 실천함으로써 보육의 질을 높일 수 있다고 하였다. 최해주, 문수백(2013)[15]은 교사-부모 파트너십은 영유아 교사의 직무만족도를 매개로 하여 영유아의 상호작용에 간접적인 영향을 미친다고 하였으며, 방글이(2015)[16]는 영아의 사회, 정서발달을 지원하기 위하여 교사-부모 간 상호 협력관계가 형성되어야 하고, 교사 스스로 효능감을 높이려는 노력이 중요하다는 연구 결과를 보고하였다.

한편 보육 기관은 영유아의 보육을 목적으로 원장, 보육교사, 그 외 교직원으로 구성된 조직으로 각 구성원이 맡은 바 임무를 수행하면서 조직만의 고유한 문화를 형성한다[17]. 어린이집의 조직문화는 기관의 규범과 동료 교사들과의 관계 및 상호작용, 교사로서 지켜야 하는 품행 등이 포함하며[18], 원장 및 동료 교사들이 공유하는 가치와 신념 혹은 교사의 행동과 태도에 영향을 미치는 상징적 행위의 총체라고 할 수 있다[19]. 보육교사는 원장과 동료교사, 학부모와 영유아들로 구성된 집단에서 근무하면서 어린이집의 조직문화를 경험하게 되며, 이는 곧 교사가 지녀야 할 자세와 역량에도 영향을 미치게 되어 결과적으로 영유아에게도 직, 간접적으로 영향을 미치게 된다[17].

어린이집 조직문화에 대한 선행연구를 살펴보면 김미현(2012)[20]은 조직문화가 긍정적이면 교사의 의욕이 높고 개방적이며 구성원 간에 협력하고자 하는 의지가 높지만, 조직문화가 부정적이면 구성원 간에 소통이 제대로 이루어지지 않으며 교사의 에너지가 낮다고 밝혔다. 류미선(2003)[21]은 어린이집 조직문화는 보육교사의 태도와 행동에도 영향을 미친다고 하였으며, 강경석과 정우영(2006)[22]은 교육기관의 유연한 조직 분위기가 형성될수록 교사의 효능감이 높다고 하였다. 김희진과 이분려(1999)[23]는 교사가 자신이 속한 조직의 문화에 대해 긍정적으로 인식할수록 교사의 교수 능력에 대한 자신감이 높아진다고 하였다. 그 밖에도 조직문화와 조직유형에 관한 연구[24], 조직의 특성에 따른 조직문화의 차이를 분석한 연구[25]가 있는데 이를 종합해보면 어린이집 조직문화는 교사효능감에 영향을 주는 매우 중요한 요인임을 예측할 수 있다.

지금까지 선행연구를 통해 보육교사의 부모-교사 협력행동과 대인관계 유능성 간의 
관계(김유정 외, 2011)[7], 교사-부모 협력관계와 교사효능감 간의 관계(방글이, 2015)[16], 어린이집 조직문화와 교사 직무만족도와의 관계(김이정, 2018)[26] 등이 밝혀졌으나, 보육교사가 인식한 교사-부모 파트너십과 어린이집 조직문화가 교사효능감에 미치는 영향을 살펴본 연구는 이루어지지 않은 실정이다. 이에 본 연구는 보육교사의 교사효능감에 영향을 미칠 것으로 예측되는 교사-부모 파트너십, 어린이집 조직문화에 대해서 관계성과 영향력을 살펴보고자 한다. 본 연구에서의 연구 결과를 통해 보육교사의 교사효능감을 증진하는 방안을 모색하며 보육서비스의 질적 향상을 도모하기 위한 프로그램 및 정책 개발에 필요한 기초자료를 제공하고자 한다.

연구문제 1. 교사-부모 파트너십, 어린이집 조직문화(관계문화, 개발문화, 위계문화, 합리문화), 교사효능감 간의 상관관계는 어떠한가?

연구문제 2. 교사-부모 파트너십과 어린이집 조직문화(관계문화, 개발문화, 위계문화, 합리문화)가 교사효능감에 미치는 상대적 영향은 어떠한가?

\section{2. 연구방법}

\section{1 연구대상}

I 시에 소재한 어린이집 교사 $(N=241)$ 를 연구대상으로 선정하였다. 교사가 근무하는 어린이집 유형의 경우에는 국공립이 $66.02 \%$ 로 가장 많았으며 민간이 $16.2 \%$, 직장이 $10.0 \%$, 가정이 $7.9 \%$ 순으로 나타났다. 연령의 경우 41 세 이상이 $27.4 \%$ 로 가장 많았으며 26 30세가 $26.6 \%, 25$ 세 이하가 $19.9 \%, 36 \sim 40$ 세가 $14.5 \%, 31 \sim 35$ 세가 $11.6 \%$ 순으로 나타났으며 최종학력의 경우 2,3 년제 대졸이 $49.4 \%$ 로 과반수 가까이 되었고, 4 년제 대졸이 $35.3 \%$, 대학원 재학 이상이 $10.8 \%$, 보육교사 교육원이 $4.6 \%$ 순으로 나타났다. 교사경력의 경우 5 7년이 $21.2 \%$ 로 가장 많았으며, 10 년 이상이 $19.9 \%, 1 \sim 3$ 년이 $19.1 \%$, 3 5년이 $16.2 \%, 1$ 년 미만이 $11.2 \%$ 순으로 나타났다.

\section{[표 1] 연구대상의 사회인구학적 특성}

[Table 1] Subjects Demographic Characteristics $(N=241)$

\begin{tabular}{|c|c|c|c|}
\hline Variable & Group & $\mathrm{n}$ & $\%$ \\
\hline \multirow{3}{*}{$\begin{array}{c}\text { Institution } \\
\text { Type }\end{array}$} & National and Public Daycare Center & 159 & 66.0 \\
& Private Daycare Center & 39 & 16.2 \\
& Daycare Center in the Workplace & 24 & 10.0 \\
& Home Daycare Center & 19 & 7.9 \\
\hline \multirow{3}{*}{ Age } & $\geq 25$ & 48 & 19.9 \\
(yr) & $26 \sim 30$ & 64 & 26.6 \\
& $31 \sim 35$ & 28 & 11.6 \\
& $36 \sim 40$ & 35 & 14.5 \\
& $41 \leq$ & 66 & 27.4 \\
\hline Academic & Vocational Center & 11 & 4.6 \\
Background & Colleage & 85 & 49.4 \\
& University & 26 & 10.8 \\
\hline
\end{tabular}




\begin{tabular}{|c|c|c|c|}
\hline & $\geq 1$ & 27 & 11.2 \\
& $1 \sim 3$ & 46 & 19.1 \\
Teaching & $3 \sim 5$ & 39 & 16.2 \\
Experience (yr) & $5 \sim 7$ & 51 & 21.2 \\
& $7 \sim 9$ & 30 & 12.5 \\
& $10 \leq$ & 48 & 19.9 \\
\hline
\end{tabular}

\section{2 연구도구}

\subsection{1 교사-부모 파트너십}

보육교사가 인식한 교사-부모 파트너십을 측정하기 위해 Ware, Barfoot, Rusher와 Owen(1995)[27]이 제작하고 Owen, Ware와 Barfood(2000)[28]이 수정한 The Caregiver-Parent Partnership Scale(교사용) 척도를 임우영과 안선희(2011)[8]가 번안한 것을 사용하였다. 본 도구는 정보공유(6문항), 정보추구(3문항), 상호관계(5문항)의 3 가지 하위요인에 걸쳐 총 14 문항으로 구성되어 있다. 하위요인별 내용을 살펴보면 '정보공유' 는 영유아에 대한 정보와 지식을 교사와 부모가 동반자적 관계를 바탕으로 공유하는 행동에 대한 문항이며, ‘정보추구' 는 영유아가 가정에서 일과 동안 있었던 일이나 행동 또는 사건 등에 대한 정보를 교사가 질문하는 문항이다. '상호관계' 는 교사가 부모와 상호 지지적인 관계를 형성하기 위해 부모에게 자녀 양육에 대해 정보를 제공하고 조언 및 격려와 관련된 문항이다. 각 문항은 Likert 5점 척도로 평정하게 되어 있으며, 점수가 높을수록 보육교사가 인지하는 교사-부모 파트너십의 정도가 높음을 의미한다. 연구도구의 신뢰도계수는 Cronbach $a=.91$ (정보공유 .83, 정보추구 .70, 상호관계 .84)이다.

\subsection{2 어린이집 조직문화}

어린이집 조직문화를 측정하기 위해, 경쟁가치모형을 기반으로 Quinn과 Kimberly (1984)[29], Quinn과 Mcgrath(1985)[30], Denison과 Spreitzer(1991)[31]가 구분한 조직문화 유형을 기초로 조인숙(2005)[32]이 개발하고 송지혜(2013)[33]가 수정·보완한 척도를 사용하였다. 본 도구는 관계문화(6문항), 개발문화(10문항), 위계문화(7문항), 합리문화(7문항)의 4가지 하위요인에 걸쳐 총 30 문항으로 구성되어 있다. 하위요인별 내용을 살펴보면 '관계문화' 는 구성원 간 가족 같은 분위기로 서로 간의 친화를 우선시하는 문화이며, '개발문화'는 성장하고자 하는 의지 및 새로운 것에 대한 도전하는 태도를 중요하게 여기는 문화를 의미한다. '위계문화'는 조직 리더의 지시와 통솔에 의한 관리를 비롯하여 업무내용의 문서화, 구성원들 각자에 대한 책임감 및 운영의 일관성을 강조하는 문화이며, ‘합리문화’는 체계적이고 효율적인 조직 관리를 강조하고, 성공적인 실천을 강조하는 문화를 의미한다. 각 문항은 Likert 5점 척도로 평정하게 되어 있으며, 4가지 조직문화 하위유형별로 점수가 높은 경우 보육교사가 재직하는 기관의 조직문화를 해당 유형으로 인식하는 정도가 높음을 의미한다. 연구도구의 신뢰도계수(Cronbach a)는 정보공유 .93, 개발문화 .91, 위계문화 .76, 합리문화는 .80이다.

\subsection{3 교사효능감}

보육교사의 교사효능감을 측정하기 위해 Enochs와 Riggs(1990)[34]에 의해 개발된 과학 교수 효능감 검사 도구(Science Teaching Efficacy Belief Instrument)를 이분려(1998)[35] 및 박현옥(2016)[36]이 수정한 도구를 사용하였다. 본 도구는 일반적 교사효능감(12문항), 
개인적 교사효능감(13문항)의 2 가지 하위요인에 걸쳐 총 25 문항으로 구성되어 있다. 하위요인별 내용을 살펴보면 '일반적 교사효능감' 은 일반적으로 교사가 영유아에게 영향을 미칠 수 있다고 생각하는 정도에 대한 일반적 사항에 대한 문항이며, '개인적 교사효능감' 은 교사로서 자기 자신이 영유아에게 영향을 미칠 수 있다고 생각하는지에 대한 개인적 사항을 의미한다. 각 문항은 Likert 5 점 척도로 평정하게 되어 있으며, 점수가 높을수록 보육교사의 교사효능감이 높음을 의미한다. 연구도구의 신뢰도계수는 Cronbach $a=.77$ (일반적 효능감 .65, 개인적 효능감 .77)이다.

\section{3 연구절차}

연구도구의 적절성 및 타당성 검토를 위해 2019년 6월 1일에서 6월 10일까지 본 연구의 연구대상에 포함되지 않는 보육교사 10 명을 대상으로 예비조사를 시행하였다. 연구도구 문항에 문제점이 발견되지 않음을 확인 후, 2019년 7월 3일부터 8월 14일까지 I 시에 소재한 보육기관 중 연구참여 의사를 밝힌 기관에 본 연구자가 직접 방문하여 설문지를 배포하거나, 우편으로 발송하였다. 총 270 부를 배부하였고, 누락 및 불성실한 답변을 한 설문지는 제외한 최종 241 부를 통계 분석에 사용하였다.

\section{4 자료분석}

본 연구에 수집된 자료는 SPSS 22.0 프로그램을 사용하여 분석하였으며, 연구대상의 사회인구학적 특성을 파악하기 위해 기술통계를 실시하였다. 이어서 연구도구의 문항 간 신뢰도를 검토하기 위하여 Cronbach' $\mathrm{s}$ a 계수를 산출하였으며, 교사-부모 파트너십과 어린이집의 조직문화 그리고 교사효능감 간의 상관관계를 알아보기 위해 Pearson의 상관관계 분석을 실시하였다. 끝으로 교사-부모 파트너십과 어린이집 조직문화가 교사효능감에 미치는 상대적 영향력을 알아보기 위하여 다중회귀분석을 실시하였다.

\section{3. 연구결과}

\section{1 교사-부모 파트너십, 어린이집 조직문화, 교사효능감 간의 관계}

교사-부모 파트너십, 어린이집 조직문화, 교사효능감 간의 관계를 알아보기 위해 상관관계분석(Pearson' s Correlation Analysis)을 실시하였으며, 그 결과는 아래의 [표 2]와 같다. 교사-부모 파트너십(전체)과 교사효능감(전체) 간에 $\mathrm{r}=.49(\mathrm{p}<.01)$ 의 정 $(+)$ 적 상관관계가 나타나 교사-부모 파트너십이 높으면 교사효능감도 높음을 알 수 있다. 이어서 어린이집 조직문화 하위요인과 교사효능감(전체)의 관계를 살펴보면 $\mathrm{r}=.29(\mathrm{p}<.01)$ 에서 $\mathrm{r}=.48(\mathrm{p}<.01)$ 의 정 $(+)$ 적인 상관관계가 나타나, 어린이집 조직문화 하위요인 점수가 높으면 교사효능감도 높음을 알 수 있다. 끝으로 교사-부모 파트너십(전체)과 어린이집 조직문화 하위요인별 관계의 경우 $\mathrm{r}=.21(\mathrm{p}<.01)$ 에서 $\mathrm{r}=.45(\mathrm{p}<.01)$ 의 정 $(+)$ 적인 상관관계가 나타나, 교사-부모 파트너십이 높으면 어린이집 조직문화의 하위요인 점수도 높음을 알 수 있다. 
[표 2] 연구변인 간 상관관계

[Table 2] Correlation among Research Variables

\begin{tabular}{|c|c|c|c|c|c|c|c|c|c|c|c|c|}
\hline \multicolumn{2}{|r|}{ 변인 } & 1 & 2 & 3 & 4 & 5 & 6 & 7 & 8 & 9 & 10 & 11 \\
\hline \multirow{4}{*}{$\begin{array}{l}\text { 교사-부모 } \\
\text { 파트너십 }\end{array}$} & 1.정보공유 & 1 & & & & & & & & & & \\
\hline & 2.정보추구 & $.68 * *$ & 1 & & & & & & & & & \\
\hline & 3.상호관계 & $.65^{* *}$ & $.75^{* *}$ & 1 & & & & & & & & \\
\hline & 4.전체 & $.88^{* *}$ & $.87 * *$ & $.91 * *$ & 1 & & & & & & & \\
\hline \multirow{4}{*}{$\begin{array}{l}\text { 어린이집 } \\
\text { 조직문화 }\end{array}$} & 5.관계문화 & $.35^{* *}$ & $.27 * *$ & $.18^{* *}$ & $.30^{* *}$ & 1 & & & & & & \\
\hline & 6.개발문화 & $.44 * *$ & $.37 * *$ & $.34 * *$ & $.43^{* *}$ & $.72 * *$ & 1 & & & & & \\
\hline & 7.위계문화 & $.20^{* *}$ & $.17^{* *}$ & $.17^{* *}$ & $.21 * *$ & $.23^{* *}$ & $.48^{* *}$ & 1 & & & & \\
\hline & 8.합리문화 & $.41^{* *}$ & $.42 * *$ & $.38^{* *}$ & $.45^{* *}$ & $.52 * *$ & $.76^{* *}$ & $.53 * *$ & 1 & & & \\
\hline \multirow{3}{*}{$\begin{array}{c}\text { 교사 } \\
\text { 효능감 }\end{array}$} & 9.일반적효능감 & $.18^{* *}$ & $.23^{* *}$ & $.34 * *$ & $.29^{* *}$ & $.15^{*}$ & $.24 * *$ & $.28 * *$ & $.33^{* *}$ & $.31 * *$ & 1 & \\
\hline & 10.개인적효능감 & $.41 * *$ & $.44 * *$ & $.45^{* *}$ & $.48 * *$ & $.32 * *$ & $.46^{* *}$ & $.19 * *$ & $.44^{* *}$ & $.45 * *$ & $.31 * *$ & 1 \\
\hline & 11.전체 & $.37 * *$ & $.42 * *$ & $.49 * *$ & $.49^{* *}$ & $.30^{* *}$ & $.45^{* *}$ & $.29 * *$ & $.48^{* *}$ & $.47 * *$ & $.77^{* *}$ & $.84 * *$ \\
\hline
\end{tabular}

${ }^{*} \mathrm{p}<.05,{ }^{*} \mathrm{p}<.01$

\section{2 교사-부모 파트너십과 어린이집 조직문화가 교사효능감에 미치는 영향}

교사-부모 파트너십, 어린이집 조직문화가 교사효능감에 미치는 영향에 대해 살펴보면 설명력은 $33 \%$ 를 설명하며 회귀식의 통계적 유의성을 검증하기 위한 $\mathrm{F}$ 값은 23.14 이고 유의확률은 .000으로 회귀식이 통계적으로 유의한 것으로 나타났다. 교사-부모 파트너십, 어린이집 조직문화의 각 요인들에 대한 유의성을 판단하기 위한 $\mathrm{t}$ 값의 유의도에 의해 교사효능감에 영향을 미치는 변수로는 교사-부모 파트너십( $\beta=.33, p<.001)$, 합리문화 $(\beta=.23, p<.05)$ 가 정 $(+)$ 적인 영향을 미치는 것으로 나타났으며 영향력의 크기는 교사-부모 파트너십, 합리문화 순으로 나타났다. 이러한 연구결과는 교사-부모 파트너십과 합리적인 조직문화가 잘 구축되어 있을수록 보육교사의 교사효능감이 높은 것으로 예측되어 교사-부모 파트너십과 어린이집의 합리적인 조직문화가 교사효능감에 긍정적인 영향을 미치고 있음을 알 수 있다.

[표 3] 다중회귀분석

[Table 3] Multiple Regression Analysis

\begin{tabular}{|c|c|c|c|c|c|c|}
\hline \multirow{2}{*}{\multicolumn{2}{|c|}{ 독립변인 }} & \multicolumn{5}{|c|}{ 보육교사의 교사효능감 } \\
\hline & & B & $\beta$ & $\mathrm{t}$ & $\mathrm{F}$ & $R^{2}$ \\
\hline \multicolumn{2}{|c|}{ 교사-부모 파트너십 } & .20 & .33 & $5.40^{* * *}$ & \multirow{5}{*}{$23.14 * * *$} & \multirow{5}{*}{.33} \\
\hline \multirow{4}{*}{$\begin{array}{l}\text { 어린이집 } \\
\text { 조직문화 }\end{array}$} & 관계문화 & -.01 & -.01 & -.17 & & \\
\hline & 개발문화 & .06 & .12 & 1.12 & & \\
\hline & 위계문화 & .03 & .05 & .73 & & \\
\hline & 합리문화 & .12 & .23 & $2.57^{*}$ & & \\
\hline
\end{tabular}




\section{4. 논의 및 결론}

본 연구는 양질의 보육 서비스를 제공하기 위해 보육교사의 교사효능감에 영향을 미치는 요인들을 살펴보고자 시행되었으며, 본 연구에서 도출된 연구 결과를 제시하고 논의하면 다음과 같다.

연구문제 1 과 관련하여 보육교사가 인식한 교사-부모 파트너십, 어린이집 조직문화, 교사효능감 간의 관계를 살펴본 결과 모두 유의미한 정(+)적 상관관계가 있는 것으로 나타났다. 교사-부모 파트너십이 높을수록 보육교사의 교사효능감이 높았다는 연구결과는 황해익, 탁정화, 김미진(2013)[37], 임경임(2010)[38]의 연구결과를 지지하며, 교사-부모 간 원활하고 유기적인 협력관계가 형성되면 교사로서 영유아의 바람직한 성장발달을 지원할 수 있는 자신감 즉 교사효능감이 높다는 방글이(2015)[16]의 연구결과와도 일치한다. 이러한 연구 결과는 보육현장에서 교사의 교사효능감을 향상하기 위해서 교사-부모 간 믿고 의지할 수 있는 건강한 파트너십이 형성되는 것이 필요함을 시사한다.

이어서 어린이집의 관계문화, 개발문화, 위계문화, 합리문화 점수가 높을수록 교사효능감 점수가 높게 나타난 연구결과는 김은진(2017)[39], 류미선(2003)[21], 박민우(2012)[40], 강경석, 정우영(2006)[23] 연구와 일치한다. 또한 보육교사는 근무하고 있는 어린이집이 관계 지향적이고 합리적인 문화가 구축되어 있다고 인지할수록 교사효능감이 높았다는 김미경, 김혜순(2018)[41] 연구결과를 비롯하여 어린이집이 보육의 효율성을 높이고 성공적인 실천을 중시하는 문화가 형성되어 있으며 구성원의 개발적 분위기가 중요하게 조성된 곳에 근무할수록 보육교사의 교사효능감이 높다는 유계숙, 김수경, 강경화, 박지혜, 황지영(2011)[42]의 연구도 맥을 같이 하고 있다. 이러한 결과는 보육교사는 구성원 간의 친화감이 있으며, 서로의 성장을 독려하고 도전을 지지하며, 업무 및 운영에서의 일관성과 체계성이 갖춰져 있고, 효율적인 조직 관리가 이루어지는 곳에서 근무할 때 본인이 영유아에게 더욱 긍정적인 영향을 미칠 수 있다고 인지하므로 보육 시설에서의 건강한 조직문화 조성이 매우 필요함을 알 수 있다.

연구문제 2 와 관련하여 교사-부모 파트너십과 어린이집 조직문화 중 합리문화가 교사효능감에 미치는 영향력을 $33 \%$ 설명하였으며, 상대적 영향력의 경우 교사-부모 파트너십이 어린이집 조직문화 중 합리문화 더욱 높은 것으로 나타났다. 본 연구의 결과는 부모와의 의사소통 빈도가 높은 교사들은 교수 효능감이 높아 영유아에게 보다 긍정적인 자극과 지원을 제공한다는 Owen, Ware, Barfoot(2000)[28], 임우영, 안선희(2011)[8], 최해주, 문수백(2013)[15]의 연구결과를 지지한다. 또한, 보육교사는 합리적 문화가 형성된 기관에 근무하는 경우 교사의 역할과 자신감 즉 교사효능감에 긍정적 영향을 받는다는 김미경(2018)[41] 연구결과를 지지한다. 이러한 결과는 교사와 부모가 영유아의 정보를 공유하며 협력하는 좋은 파트너십을 형성하고, 어린이집이 합리적인 조직문화가 형성된다면 보육교사의 교사효능감에 영향을 주어 교사로서의 자신감과 보람을 가지고 보육의 질 제고를 위해 더욱더 노력할 수 있음을 시사한다.

본 연구결과를 토대로 살펴보면, 보육현장에서 학부모와의 협력관계 형성에 어려움이 있는 교사에게 교사-부모 파트너십의 영향력 또는 중요성을 설명하여 학부모와의 협력 관계 형성에 대한 적극적인 동기부여 기회가 제공되어야 할 것이다. 또한, 교사의 경력, 담당 영유아의 연령 및 발달 상황, 학부모 관심사 등 교사와 학부모의 다양한 특징을 고려하여 서로 건강한 파트너십을 구축하여 유지할 수 있는 구체적 방법을 알려주는 연수가 이루어져야 할 것으로 생각한다. 더불어 어린이집에 합리적인 조직문화가 잘 
구축되어 있을수록 교사효능감이 높은 것으로 예측되는 만큼 체계적이고 효율적인 조직 관리와 능동적이고 합리적인 조직문화 형성을 높이는 방안을 마련하여 보육교사의 교사효능감을 증진함으로써 질 높은 보육 환경을 조성할 수 있도록 지원해야 할 것이다.

본 연구에서는 보육교사를 대상으로 설문지를 이용하여 자료를 수집하여 답변이 객관적이지 않을 수 있다는 제한점이 있다. 따라서 후속 연구에서는 관찰법, 면담법과 같이 다양한 연구방법이 추가로 적용된 연구가 이루어질 필요가 있다. 끝으로 본 연구에서 다뤄진 교사-부모 파트너십과 어린이집 조직문화 변인 외에 교사효능감에 영향을 주는 다양한 변인을 찾는 후속 연구가 이루어져야 할 것으로 생각한다.

\section{References}

[1] J. R. Cho, A research on Professional Recognitions and Job Satisfactions of Early Childhood Teachers, Soongsil University, Master's thesis, pp.1-53, (2012)

[2] A. Bandura, Self-efficacy: The Exercise of Control, W.H. Freeman \& Company, pp.36-78, (1997)

[3] P. T. Ashton, Teacher efficacy: A Motivational Paradigm for Effective Teacher Education, Journal of Teacher Education, (1984), Vol.35, No.5, pp.28-32, DOI : 10.1177/002248718403500507

[4] H. J. Gu, J. H. Lee, The Relationship among Young Children's Playfulness, Ego Resilience and Teachers' Teaching Efficacy about Children's Play by Gender, Journal of Educational Innovation Research, Vol.29, No.4, pp.221-241, DOI : 10.21024/pnuedi.29.4.201912.221

[5] E. S. Shin, The Effects of Teacher's Efficacy Beliefs about Play on teache-Child Interaction and Children's Play, Korean Journal of Early Childhood Education, (2000), Vol.20, No.1, pp.27-43.

[6] S. N. Kim, The Relationships among Communicative Competence, Teaching Efficacy and Job Satisfaction of Early Childhood Teachers, Kyounggi University, Master's thesis, pp.1-75, (2012)

[7] Y. J. Kim, J. H. Park, S. H. Ahn, The Effects of Early Child Care Teachers`Communication Competence, Interpersonal Competence and Teacher Self-efficacy to Enlist Parental Involvement on Parent-Teacher Partnerships, Korean Journal of Child Studies, (2012), Vol.33, No.5, pp.71-89, DOI :10.5723/KJCS.2012.33.5.71

[8] W. Y. Lim, S. H. Ahn, Relationships between Teacher-Parent Partnerships and Teacher-Child Interactions, Journal of Future Early Childhood Education, (2011), Vol.18, No.4, pp.323-350, UCI: G704-000819.2011.18.4.008

[9] C. M. Kang, Consideration of Teacher Variables for Constructive Instructional-Learning Environments : Mediating Effects of Teacher Efficacy Between Early Childhood Teacher-Parent Partnership Behavior and Teacher Job Satisfaction, Ewha Womans University, Master's thesis, pp.1-90, (2017)

[10] Guidelines for Open Daycare Centers - For Daycare Centers, Ministry of Health and Welfare, pp.1-31, (2017)

[11] W. Y. Park, The Relationship between Teacher-Parent Partnership and Teacher-Infant Interaction Perceived by Infant Teacher, Kookmin University, Master's thesis, pp.1-53, (2015)

[12] K. S. Jeong, H. H. Son, J. Y. Kim, Relationship between Teacher-Parent Cooperation and Competence for Building Early Childhood Educational Community: Mediating Effect of Psychological Empowerment, The Korea Association of Child Care and Education, (2019), No.114, pp.45-67, DOI: 10.37918/kce.2019.01.114.45

[13] C. J. Lee, An Analysis of Mutual Perception in the Mother-preschool Teacher Relationship, Choongang University, Master's thesis, pp.1-92, (2002)

[14] H. H. Jeong, A study on the Effect of Trust of a Child Care Teacher toward the Principal and Co-workers and Cooperation with Parents on Happiness of the Teacher, Choongang University, Master's thesis, pp.1-79, (2019)

[15] H. J. Choi, S. B. Moon, A Structural Relationships among Teacher-Young Children Interaction, Childcare Teacher`s Work-satisfaction, Day Care Director`s Transformational Leadership, and Parent-Caregiver Partnership, Journal of 
Future Early Childhood Education, (2013), Vol.20, No.3, pp.69-88, UCI : G704-000819.2013.20.3.008

[16] G. Y. Bang, An impact of the parent-teacher collaboration and nursing teacher' teacher efficacy on the social emotional development of infants, Kyounghee University, Master's thesis, pp.1-67, (2015)

[17] J. A. Kim, J. H. Lee, Organizational Effectiveness of Child Care Centers Perceived by Child Care Practitioners, Journal of Future Early Childhood Education, (2009), Vol.16, No.3, pp.25-57, UCI: G704-000819.2009.16.3.011

[18] M. H. Kim, A study on Edu-care Facilities' Organizational Culture and Teachers' Job Satisfaction, Choongang University, Master's thesis, pp.1-119, (2011)

[19] M, Y. Kim, A Study on the Effect of Organizational Culture Perception of the Child Care Center Teachers' Organizational Commitment, Hanyang University, Master's thesis, pp.1-84, (2010)

[20] M. H. Kim, Kindergarten Teachers' Teaching Flow and Differences according to Variables and Relationship with Organizational Climate of Kindergarten, Ewha Womans University, Master's thesis, pp.1-85, (2012),

[21] M. S. Rye, A Study on Autonomous Supervision in Kindergarten as per Organizational Culture of the Early Childhood Education Institutions Recognized by Teachers, Duksung Women's University, Master's thesis, pp.1-134, (2003)

[22] K, S. Kang, W. Y. Jung, Analysis of the Causal Relation Among School Organizational Culture, Teacher Efficacy, and School Organizational Commitment, The Journal of Korean Teacher Education, (2006), Vol.23, No.1, pp.397-419, UCI: G704-000867.2006.23.1.013

[23] H. J. Kim, B. R. Lee, A Study on Factors Influencing Teachers' Sense of Efficacy, The Journal of Korean Teacher Education, (1999), Vol.16, No.1, pp.161-181.

[24] J. H. Ahn, H. J. Yu, The Study of Child Care Teachers` Organizational Culture and Organization Effectiveness, Korean Journal of Child Education and Care, (2009), Vol.9, No.3, pp.25-40, UCI: G704-000867.2006.23.1.013

[25] K. J. Jung, K. S. Sin, A Study on the Relationship between Culture and Environment of Kindergarten Organization, Korea Journal of Child Care and Education, (2000), Vol.20, pp.1-29.

[26] E. J. Kim, The Effects of Childcare Teacher's Perception of the Organization Communication and Organizational Culture on their Job Satisfaction, Konkuk University, Master's thesis, pp.1-62, (2018)

[27] A. M. Ware, B. Barfoot, A. S. Rusher, M. T. Owen, The Caregiver Role in the Parent-caregiver Partnership: Its Relationship to the Child Care Environment, Poster presented at the Biennial Meeting of the Society for Research in Child Development, Indianapolis, (1995)

[28] M. T. Owen, A. M. Ware, B. Barfood, Caregiver-mother Partnership Behavior and the Quality of Caregiver-child and Mother-child Interactions, Early Childhood Research Quarterly, (2000), Vol.15, No,3, pp.413-427, DOI: 10.1016/S0885-2006(00)00073-9

[29] R. E. Quinn, J. R. Kimberly, Paradox, Planning, and Perseverance: Guidelines for Managerial Practice, Homewood, pp. 295-313, (1984)

[30] R. E. Quinn, M. R. Mcgrath, The Transformation of Organizational Cultures: A Competing Values Perspective, Sage Publications, pp.315-334, (1985)

[31] D. R. Denison, G. M. Spreitzer, Organizational Culture and Organizational Development: A Competing Values Approach, Organizational Change and Development, (1991), Vol.5, pp.1-21.

[32] I. S. Cho, A Study on the Relationship between the Quality of Child Care Service and the Organization Culture of Child Care Center, Duksung Women's University, Doctoral dissertation, pp.1-132, (2005)

[33] J. H. Song, An Effect of Nursery Facility's Organizational Culture on Teaching Profession Ethical Awareness Kyoungpook National University, Master's thesis, pp.1-66, (2013)

[34] L. G. Enochs, I. M. Riggs, Further Development of an Elementary Science Teaching Efficacy Belief Instrument: A Preservice Elementary Scale, School Science and Mathematics, (1990), Vol.90, No.8, pp.694-706, DOI : $10.1111 / \mathrm{j} .1949-8594.1990 . t b 12048 . x$

[35] B. R. Lee, The Relationship Among Organizational Climate, Job Satisfaction and Teacher's Sense of Efficacy in the 
Kindergartens, Ewha Womans University, Master's thesis, pp.1-65, (1998)

[36] H .O. Park, Relationships among the Director's Servant Leadership Perceived by Child-care Teacher and Child-care Teacher's Job Satisfaction : the Mediating Effects of Teacher, Kyunghee University, Master's thesis, pp.1-68, (2016)

[37] H. I. Hwang, J. H. Tak, M. J. Kim, Impact of Teaching Flow and Teacher Efficacy on Commitment on Early Childhood Teachers, Korean Journal of Early Childhood Education, (2013), Vol.33, No.4, pp.95-117, DOI: $10.18023 / \mathrm{kjece} .2013 .33 .4 .005$

[38] K. I. Lim, Self-Efficacy and Reaction of Teachers by Parents` Noncooperation Attitude, Journal of Ethics Education Studies, (2010), No.21, pp.185-200, UCI: G704-001561.2010..21.002

[39] E. J. Kim, The Effect of Early Childhood Teacher's Perception of Head Person's Emotional Leadership and Organizational Culture at Child-care Centers on Teacher's Efficacy, Choongang University, Master's thesis, pp.1-96, (2017)

[40] M. W. Park, The Relationship Between Teachers' Perceived Organizational Culture of the Early-Childhood Educational Institution and their Empowerment, Hansung University, Master's thesis, pp.1-61, (2012)

[41] M. K. Kim, The Effects of the Organization Culture of Daycare Centers on the Caring Thinking and the Effectiveness of Teachers, DongKuk University, Master's thesis, pp.1-97, (2018)

[42] G. S. Yoo, S. K. Kim, K. H, Kang, J. H. Park, J. Y. Hwang, Relationships among Organizational Culture of Child Care Centers, Teachers` Background Variables, Teacher Efficacy, and Job Stress of Novice Child Care Teachers, Journal of Future Early Childhood Education, (2011), Vol.18, No.3, pp.81-104, UCI: G704-000819.2011.18.3.007 